\title{
Exhaust emission from a vehicle engine operating in dynamic states and conditions corresponding to real driving
}

\begin{abstract}
The article presents the exhaust emission results from a diesel engine in dynamic states of engine operation in the driving tests: NEDC (New European Driving Cycle) and Malta test, developed at the Poznan University of Technology. The NEDC and Malta tests were carried out as simulations on the engine test bench mimicking the driving tests conditions. The test results of the emission of carbon monoxide, hydrocarbons and nitrogen oxides obtained in each of the tests were presented. The dynamic states have been classified depending on the time derivative value of the torque and engine rotational speed. Both the positive and negative as well as zero time derivative values of torque and rotational speed were considered. Therefore, overall six types of dynamic states were analyzed. A high sensitivity of exhaust emission to various types of dynamic states was found. The exhaust emission sensitivity to dynamic states in the Malta test was found to be higher than for the NEDC test, although these tests have similar properties (average rotational speed and average torque). This is due to the fact that the NEDC test is created on the basis of the similarity of zero-dimensional characteristics of the car's speed characteristic, whereas the Malta test was designed in accordance with the principle of faithful representation in the time domain of the NEDC speed curve.
\end{abstract}

Keywords: combustion engines, exhaust emissions, dynamic states

\section{Introduction}

The functional properties of internal combustion engines depend on the operating states of the engines, which means also on the occurrence of dynamic states of operation [3-8]. As operating states of internal combustion engines, one can consider - in thermally stabilized conditions - the quantities characterizing the engine operation. Therefore, the engine operating conditions that were considered for analysis included: rotational speed and torque, characterizing the engine load [6].

The exhaust emissions [3, 4, 6-8] are particularly important among the properties of internal combustion engines. While the influence of static states of engines' operation on exhaust emission is possible to evaluate unambiguously as a result of empirical research, the diversity of types of dynamic states prevents such unambiguity of test results [6]. Therefore, the exhaust emission testing taking into account dynamic states is usually carried out in dynamic tests adopted as standards. As a result of such tests, averaged value results are obtained, characterizing the total effect of these states, both dynamic and static, on the exhaust emission. Such tests are carried out in type approval procedures. It is much more difficult to try to assess specific types of dynamic states on the operating properties of internal combustion engines. The results obtained this way [3, 4, 6-8] are, however, difficult to generalize.

In this work, attempts have been made to test the emission of pollutants from the compression-ignition engine in dynamic states in tests: NEDC (New European Driving Cycle) [9] and the Malta test [1, 2], developed at Poznan University of Technology to simulate the NEDC test in accordance with the similarity criterion of zero dimensional characteristics of the vehicle speed characteristic.

\section{Test object and measuring equipment}

The test object was a Fiat 1.3 JTD (MultiJet) engine. It was a 4-cylinder compression-ignition engine with turbocharging with displacement of $1.3 \mathrm{dm}^{3}$, and having a Euro 4 emission class.

Engine dynamometer tests were carried out at the AVL Dynoroad $120 \mathrm{~kW}$ that enabled testing in dynamic conditions. The dynamometer software enables simulation of the operating states of an internal combustion engine corresponding to the engine operation in the conditions of vehicle movement. As a result, it was possible to test the engine on the test bench simulating real vehicle operating conditions for a Fiat Idea passenger car, in the NEDC and Malta tests.

The exhaust gas analysis was performed with the Semtech DS analyzer. The analyzer meets the ISO 1065 requirements in the field of exhaust emissions testing with PEMS systems. The Semtech DS analyzer is equipped with the following measuring modules:

- FID (Flame Ionization Detector) for determining hydrocarbon concentration,

- NDUV type analyzer (Non-Dispersive Ultraviolet) to measure the concentration of nitric oxide and dioxide,

- NIDR (Non-Dispersive Infrared) type analyzer to measure carbon monoxide and carbon dioxide concentration, - electrochemical analyzer for oxygen concentration determination.

In addition to measuring the concentration of exhaust components, the Semtech DS analyzer also allows the measurement of the exhaust gases mass flow.

Measurement values in dynamic conditions were recorded at a frequency of $10 \mathrm{~Hz}$.

The test object and measuring apparatus are described in detail in $[1,2]$. 


\section{Test results}

Figures 1 and 2 show the rotational speed characteristic in the NEDC and Malta tests, and in Figures 3 and 4 the relative torque characteristic in these tests.

The relative torque for a specific engine speed is defined as the torque ratio for this speed and the maximum torque for the same speed:

$$
M_{e r}(n)=\frac{M_{e}(n)}{M_{e \max }(n)}
$$

where: $M_{e}(n)$ - torque at engine speed $n, M_{e} \max (n)-$ maximum torque at engine speed $n, n-$ engine speed.

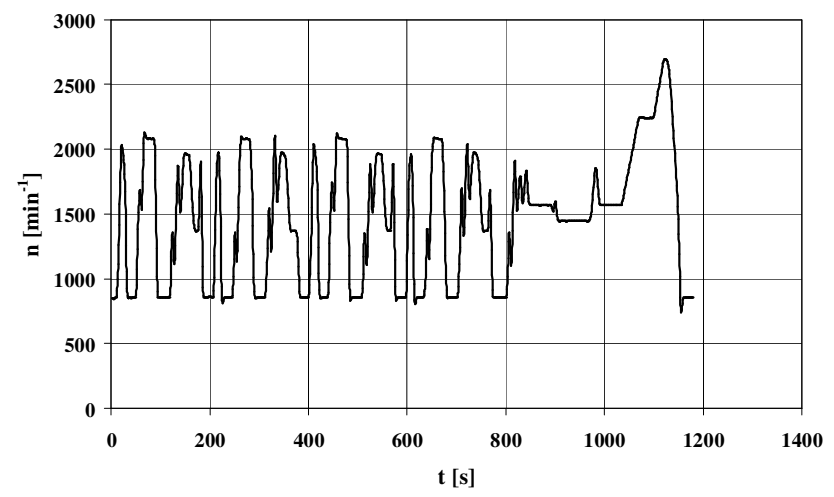

Fig. 1. Engine speed characteristic for the NEDC test

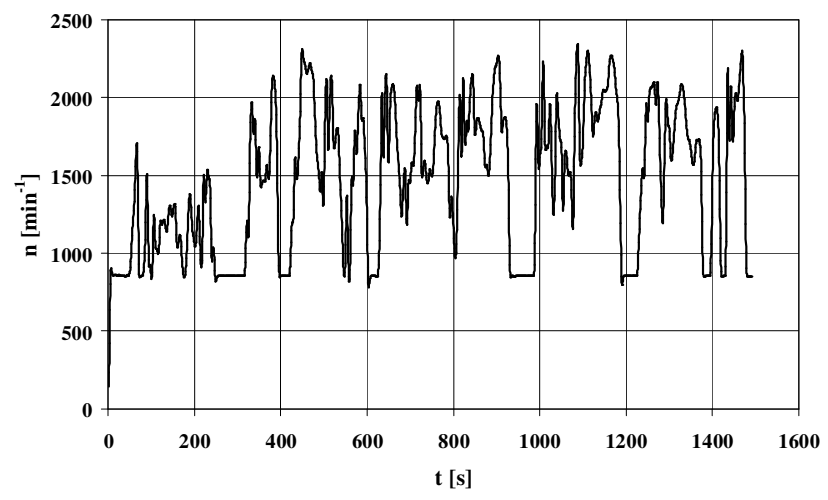

Fig. 2. Engine speed characteristic for the Malta test

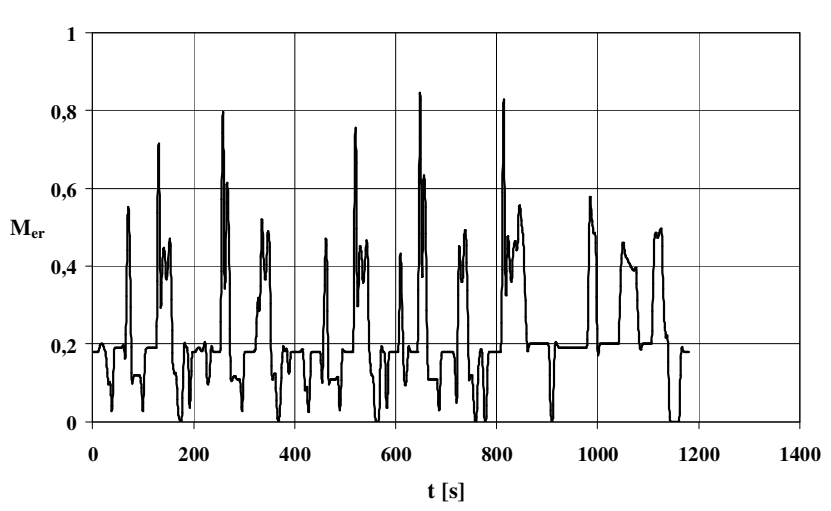

Fig. 3. Relative torque characteristic for the NEDC test

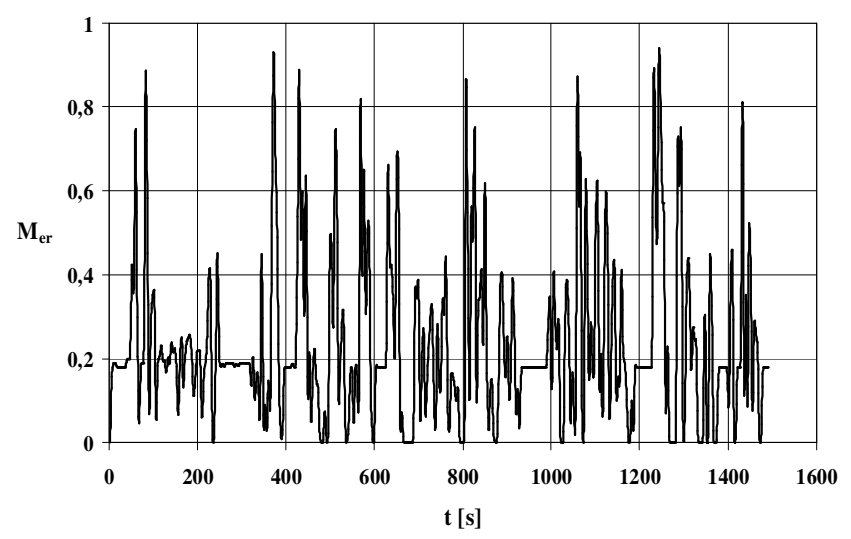

Fig. 4. Relative torque characteristic for the Malta test

The average values of rotational speed and relative torque are similar for both tests - Fig. 5 and 6 , while the differences occur in the case of the variation coefficient (Fig. 7 and 8) - the relative coefficient of variation of the torque for the Malta test is noticeably greater (relative difference of around 0.3) - Fig. 8.

Figures 9-14 show the exhaust emission intensity characteristics of carbon monoxide, hydrocarbons and nitrogen oxides in the NEDC and Malta tests.

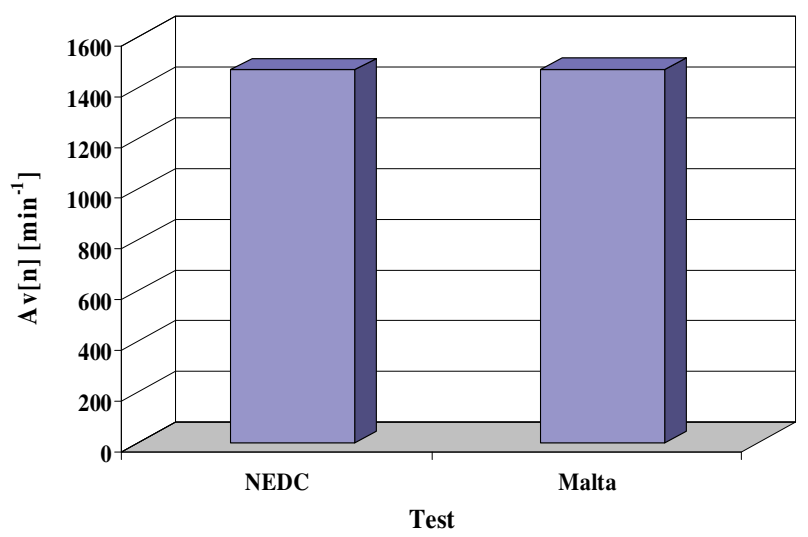

Fig. 5. Average engine speed value in the NEDC and Malta tests

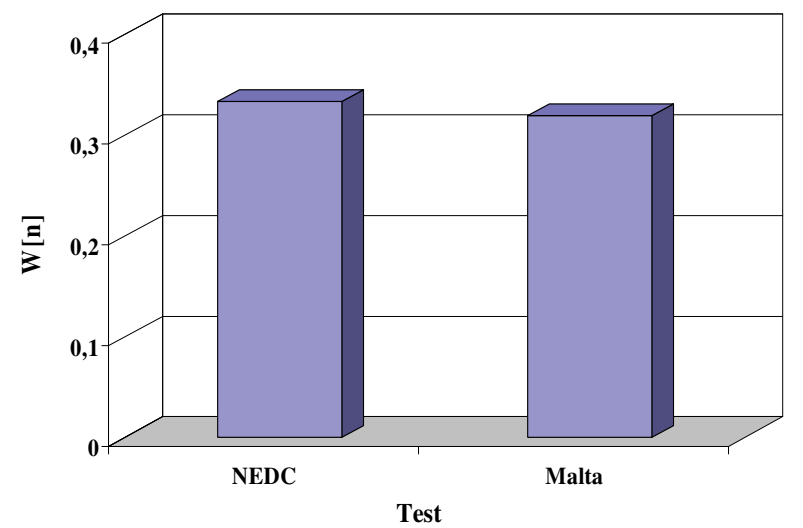

Fig. 6. Rotational speed coefficient of variation in NEDC and Malta tests 


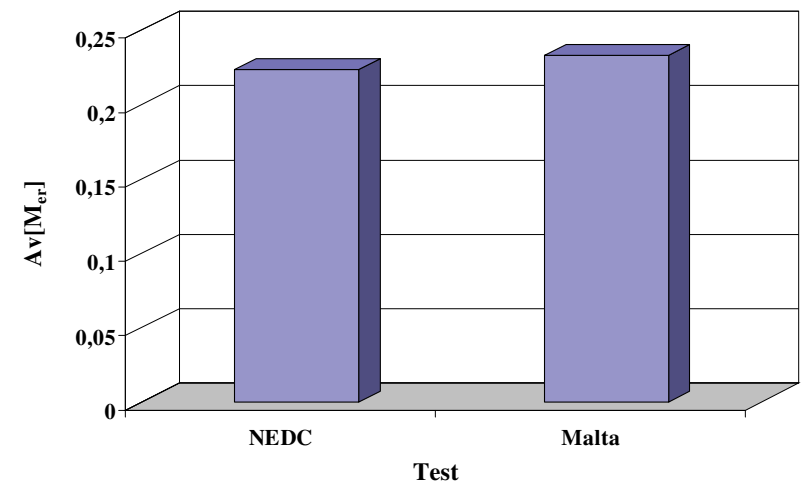

Fig. 7. Mean relative torque value in the NEDC and Malta tests

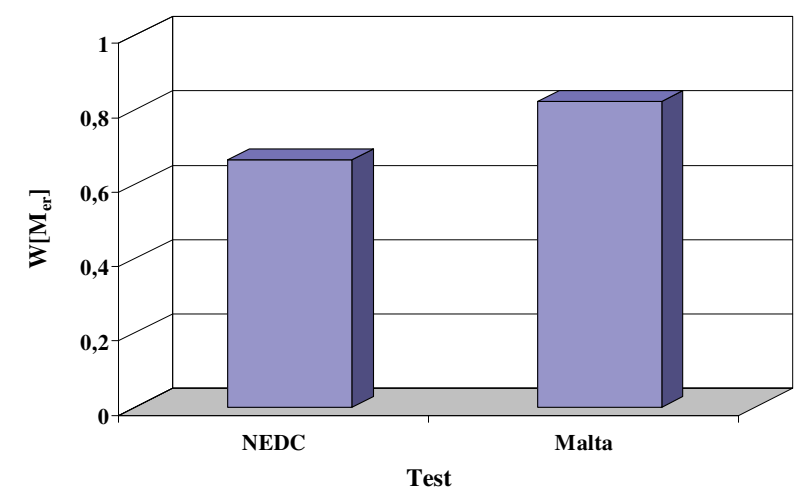

Fig. 8. The relative torque variation coefficient in the NEDC and Malta tests

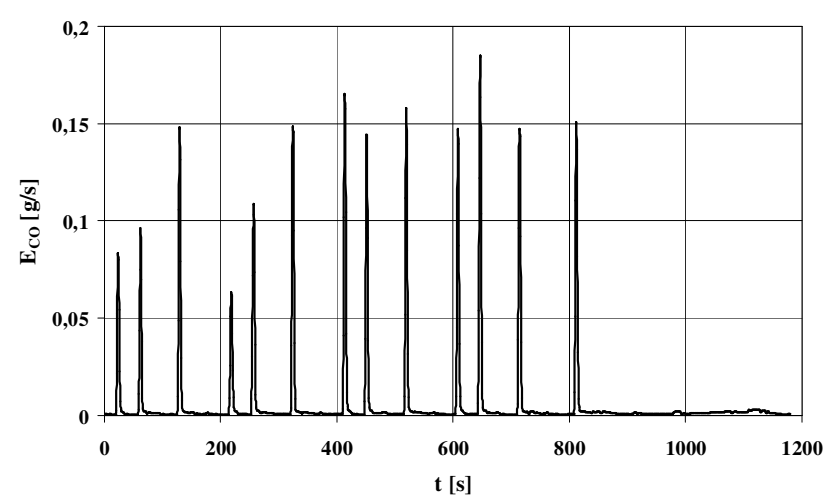

Fig. 9. The emission intensity of carbon monoxide in the NEDC test

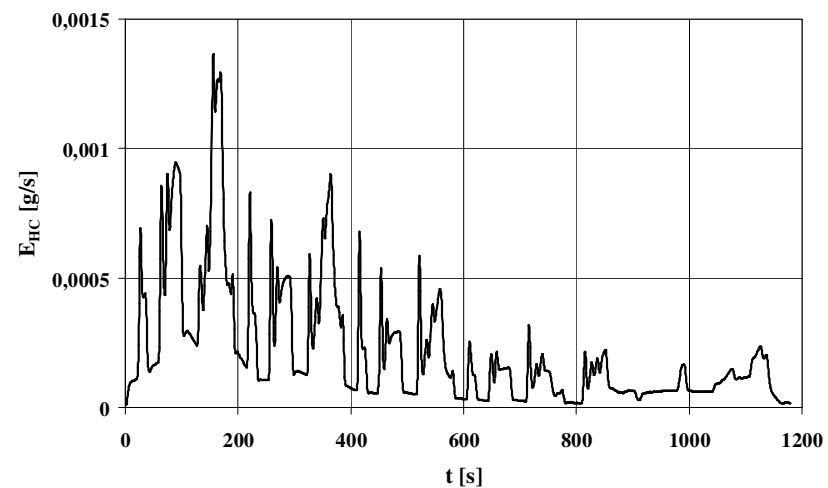

Fig. 10. The emission intensity of hydrocarbons in the NEDC test

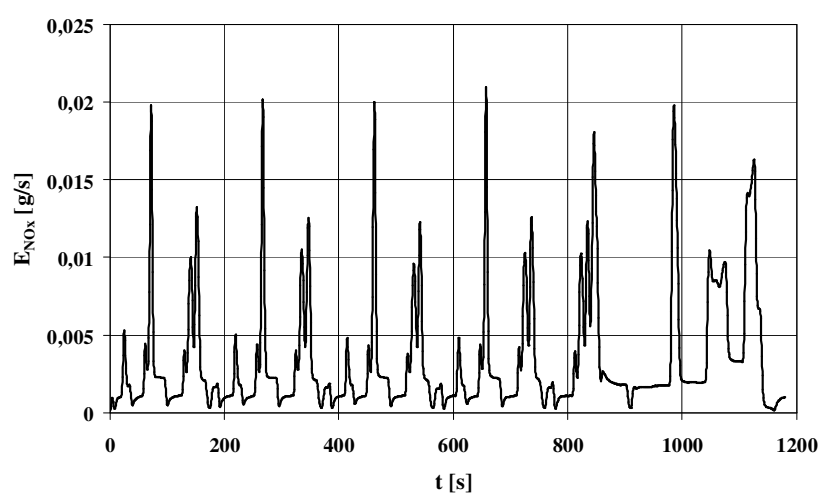

Fig. 11. The emission intensity of nitrogen oxides in the NEDC test

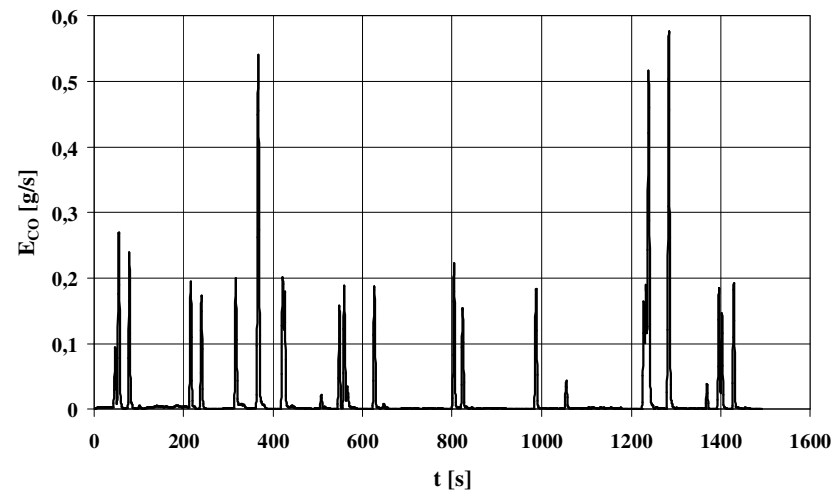

Fig. 12. The emission intensity of carbon monoxide in the Malta test

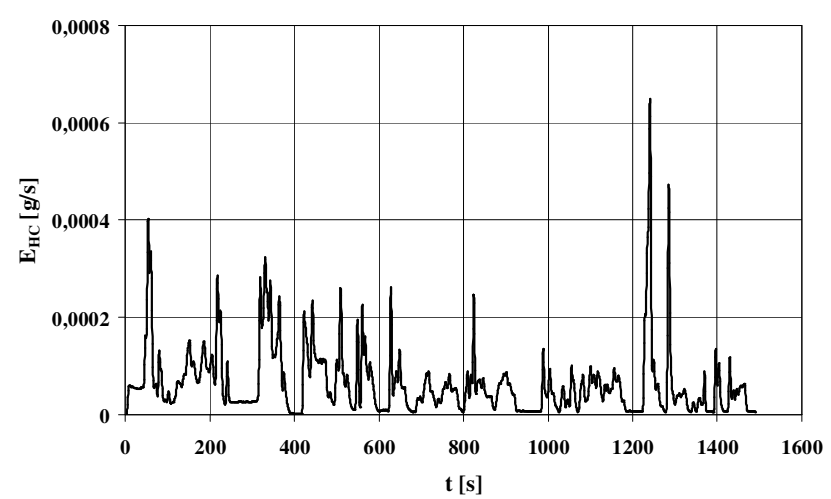

Fig. 13. The emission intensity of hydrocarbons in the Malta test

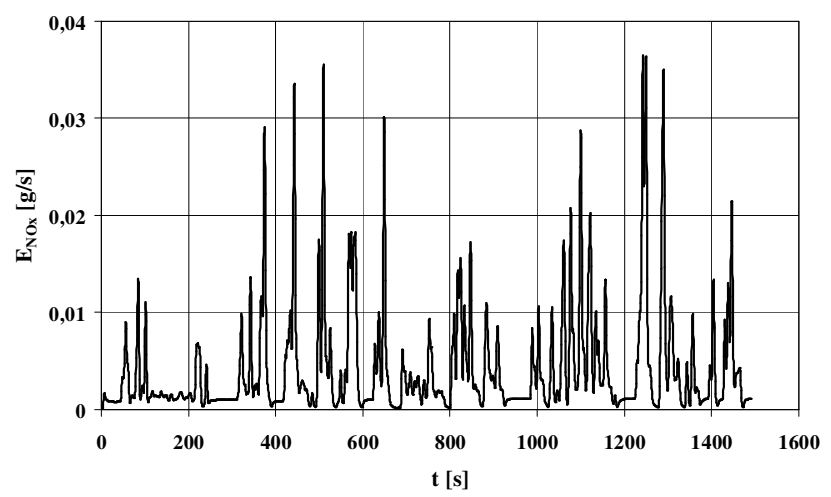

Fig. 14. The emission intensity of nitrogen oxides in the Malta test 


\section{Test results analysis}

The following defined conditions are accepted as basic dynamic states of the engine operation:

\begin{tabular}{|c|c|c|}
\hline$\frac{\mathrm{dn}}{\mathrm{dt}}<0$ & $\frac{\mathrm{dn}}{\mathrm{dt}}=0$ & $\frac{\mathrm{dn}}{\mathrm{dt}}>0$ \\
\hline$\frac{\mathrm{d} \mathrm{M}_{\mathrm{e}}}{\mathrm{dt}}<0$ & $\frac{\mathrm{dM}_{\mathrm{e}}}{\mathrm{dt}}=0$ & $\frac{\mathrm{dM}_{\mathrm{e}}}{\mathrm{dt}}<0$ \\
\hline
\end{tabular}

In addition, dynamic states related to both rotational speed and relative torque can be considered:

$$
\begin{array}{|l|l|l|}
\hline \frac{\mathrm{dn}}{\mathrm{dt}}<0 \wedge \frac{\mathrm{dM}_{\mathrm{e}}}{\mathrm{dt}}<0 & \frac{\mathrm{dn}}{\mathrm{dt}}<0 \wedge \frac{\mathrm{dM}_{\mathrm{e}}}{\mathrm{dt}}=0 & \frac{\mathrm{dn}}{\mathrm{dt}}<0 \wedge \frac{\mathrm{dM}_{\mathrm{e}}}{\mathrm{dt}}>0 \\
\hline \frac{\mathrm{dn}}{\mathrm{dt}}=0 \wedge \frac{\mathrm{dM}_{\mathrm{e}}}{\mathrm{dt}}<0 & \frac{\mathrm{dn}}{\mathrm{dt}}=0 \wedge \frac{\mathrm{dM}_{\mathrm{e}}}{\mathrm{dt}}=0 & \frac{\mathrm{dn}}{\mathrm{dt}}=0 \wedge \frac{\mathrm{dM}_{\mathrm{e}}}{\mathrm{dt}}>0 \\
\hline \frac{\mathrm{dn}}{\mathrm{dt}}<0 \wedge \frac{\mathrm{dM}}{\mathrm{dt}}<0 & \frac{\mathrm{dn}}{\mathrm{dt}}<0 \wedge \frac{\mathrm{d} \mathrm{M}_{\mathrm{e}}}{\mathrm{dt}}=0 & \frac{\mathrm{dn}}{\mathrm{dt}}<0 \wedge \frac{\mathrm{dM_{ \textrm {e } }}}{\mathrm{dt}}>0 \\
\hline
\end{array}
$$

The time derivative constancy condition was taken with an accuracy of \pm 0.02 of the derivative range with respect to time. Figures $15-20$ show the average value of exhaust emission intensity in the NEDC test and in states corresponding to the negative, zero and positive speed derivative relative to time values and in the states corresponding to the negative, zero and positive time derivative values of the relative torque.

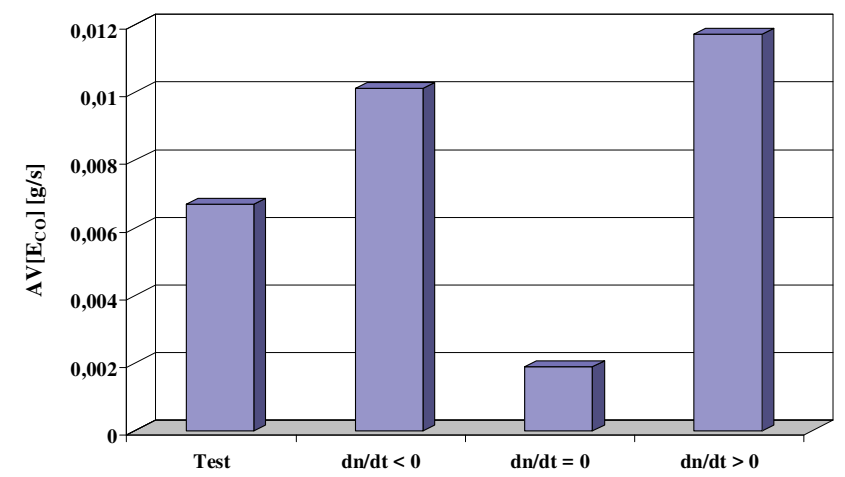

Fig. 15. The average value of the carbon monoxide emission in the NEDC test and in the states corresponding to the negative, zero and positive time derivative values of the engine speed

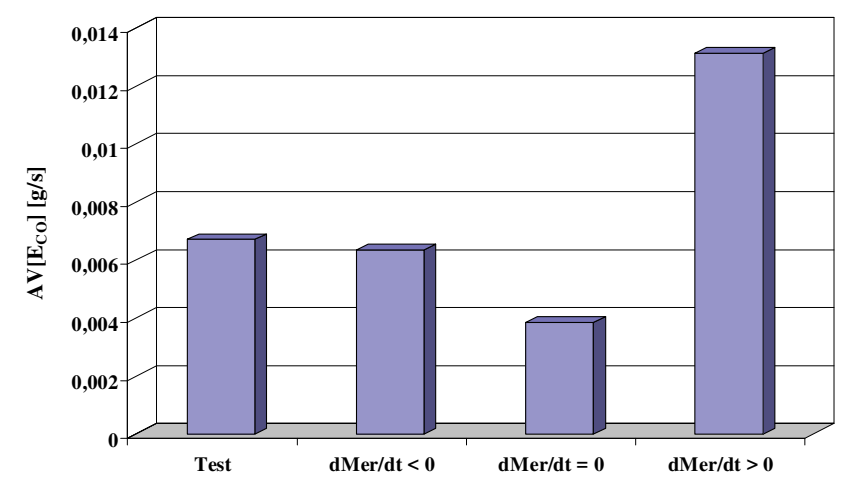

Fig. 16. The average value of the carbon monoxide emission in the NEDC test and in the states corresponding to the negative, zero and positive time derivative values of the engine torque

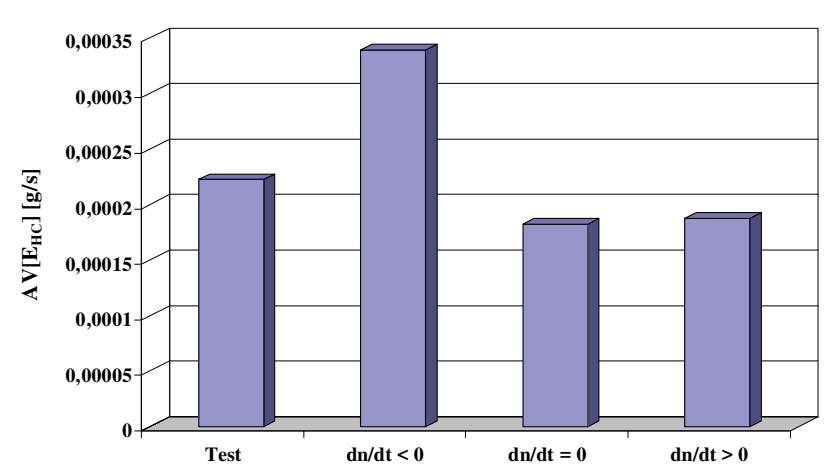

Fig. 17. The average value of the hydrocarbons emission in the NEDC test and in the states corresponding to the negative, zero and positive time derivative values of the engine speed

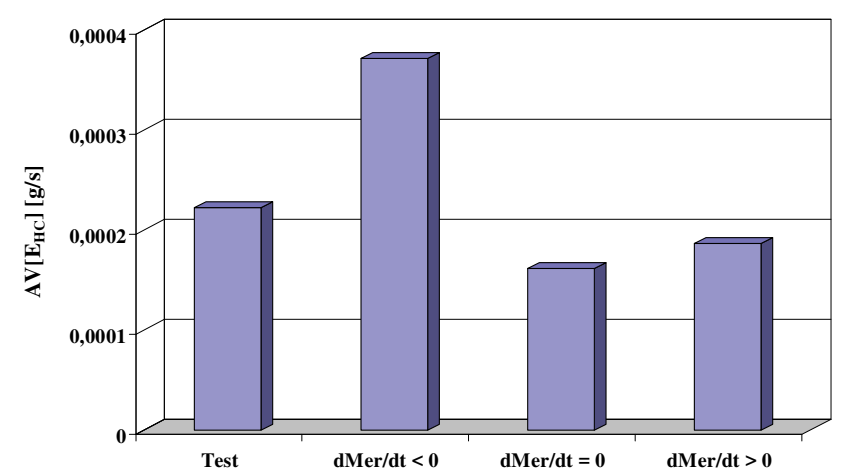

Fig. 18. The average value of the hydrocarbons emission in the NEDC test and in the states corresponding to the negative, zero and positive time derivative values of the engine torque

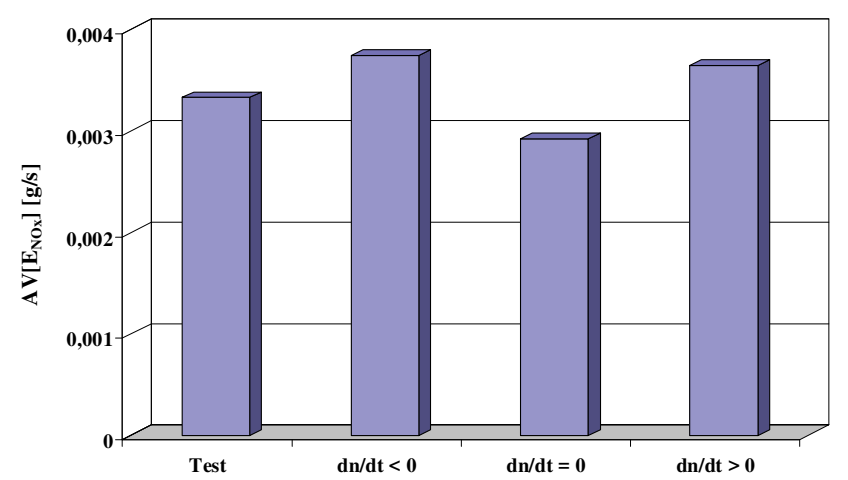

Fig. 19. The average value of the nitrogen oxides emission in the NEDC test and in the states corresponding to the negative, zero and positive time derivative values of the engine speed

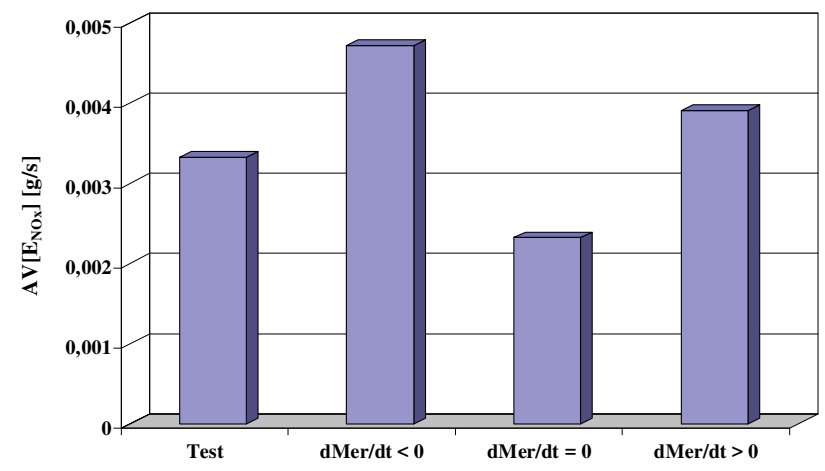

Fig. 20. The average value of the nitrogen oxides emission in the NEDC test and in the states corresponding to the negative, zero and positive time derivative values of the engine torque 
Figures 21-26 show the average value of the exhaust emission intensity in the Malta test and in states corresponding to the negative, zero and positive time derivative values of the engine speed and in the states corresponding to the negative, zero and positive time derivative values of the relative torque.

Figures 27-32 present a comparison of the mean exhaust emission intensity in the test and in states corresponding to the negative, zero and positive values of the engine speed derivative with respect to time - for the NEDC and Malta tests.

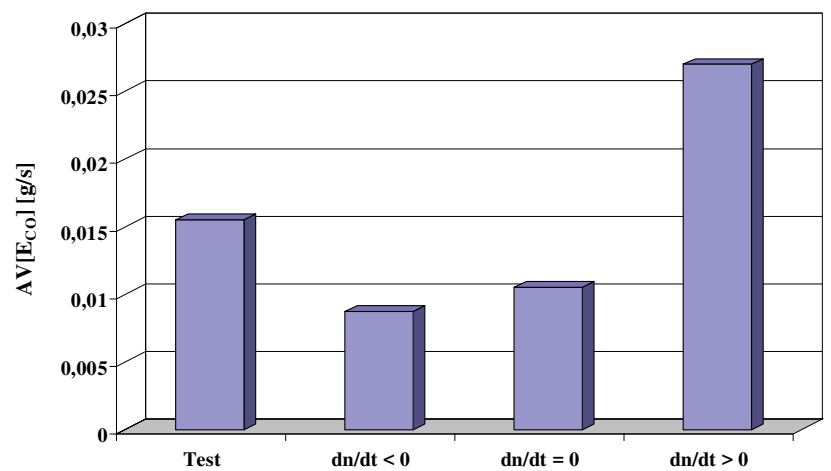

Fig. 21. Mean value of the carbon monoxide exhaust emission in the Malta test and in the states corresponding to the negative, zero and positive values of the engine speed derivative with respect to time

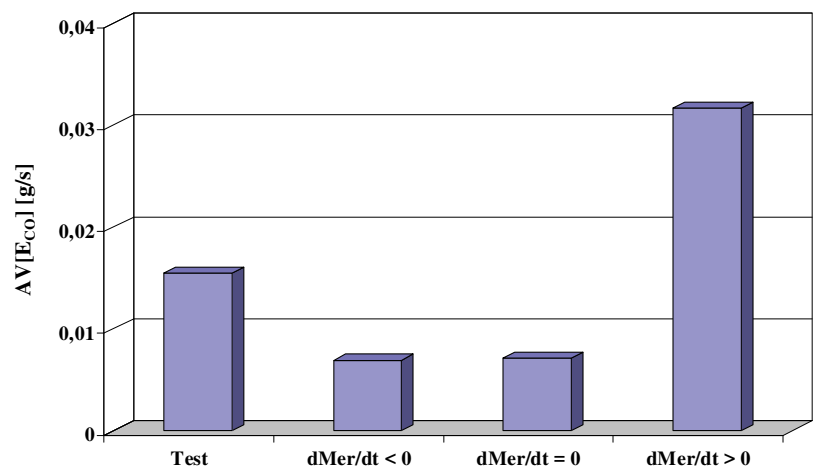

Fig. 22. Mean value of the carbon monoxide exhaust emission in the Malta test and in the states corresponding to the negative, zero and positive values of the engine torque derivative with respect to time

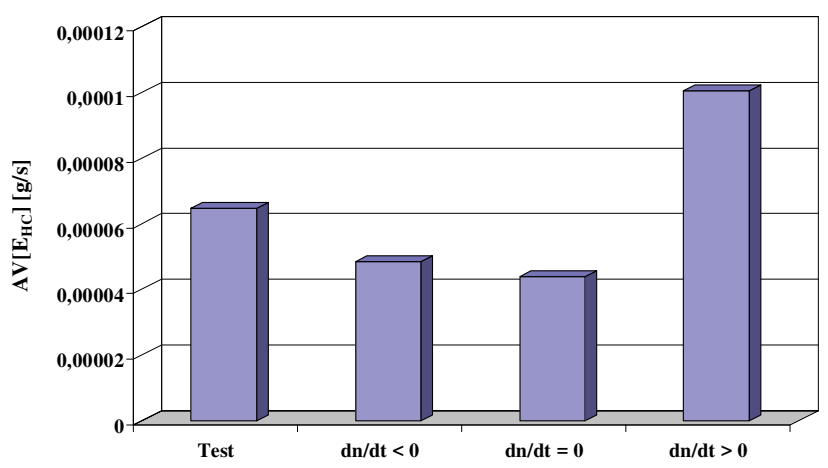

Fig. 23. Mean value of the hydrocarbons exhaust emission in the Malta test and in the states corresponding to the negative, zero and positive values of the engine speed derivative with respect to time

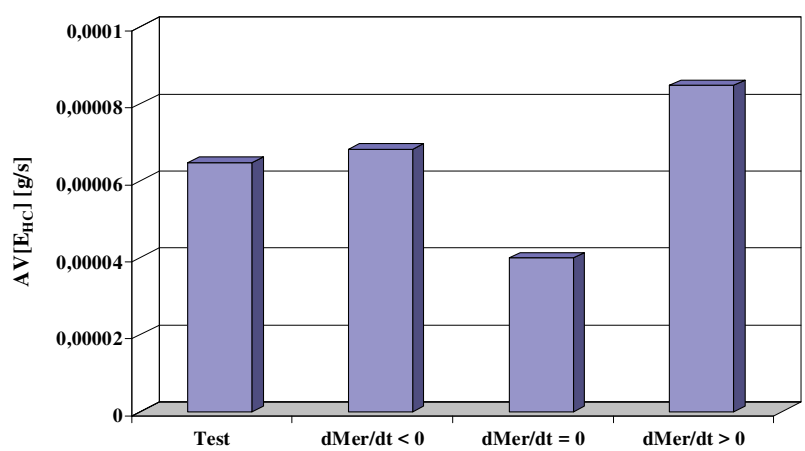

Fig. 24. Mean value of the hydrocarbons exhaust emission in the Malta test and in the states corresponding to the negative, zero and positive values of the engine torque derivative with respect to time

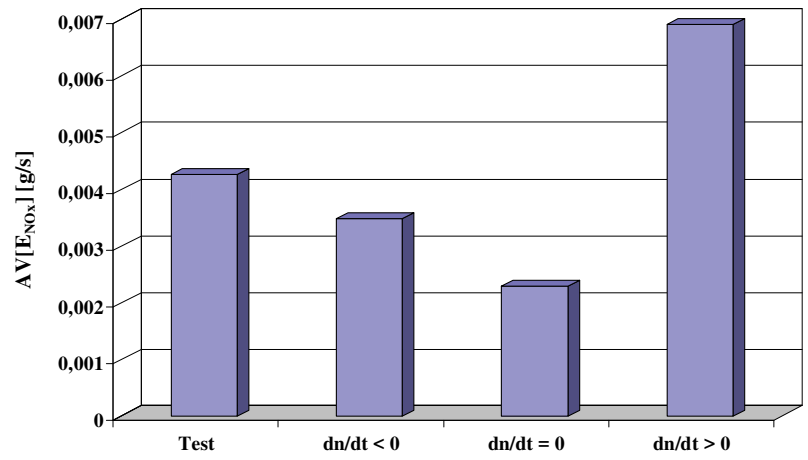

Fig. 25. Mean value of the nitrogen oxides exhaust emission in the Malta test and in the states corresponding to the negative, zero and positive values of the engine speed derivative with respect to time

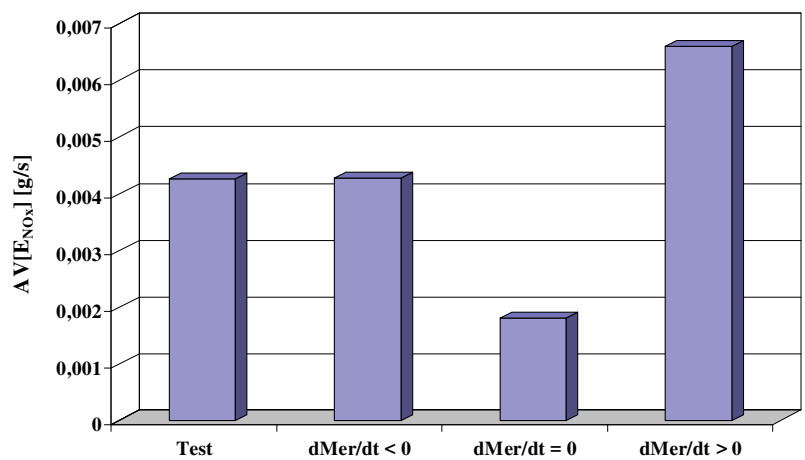

Fig. 26. Mean value of the nitrogen oxides exhaust emission in the Malta test and in the states corresponding to the negative, zero and positive values of the engine torque derivative with respect to time

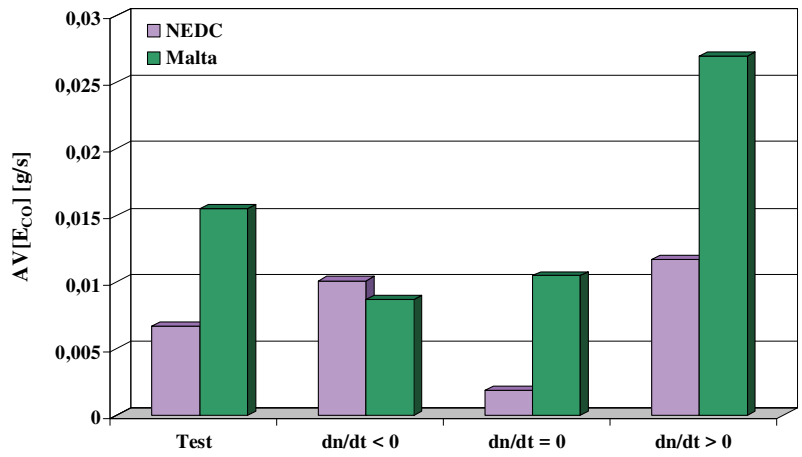

Fig. 27. Comparison of the mean carbon monoxide emission value in the test and in the states corresponding to the negative, zero and positive values of the engine speed derivative with respect to time - for the NEDC and Malta tests 


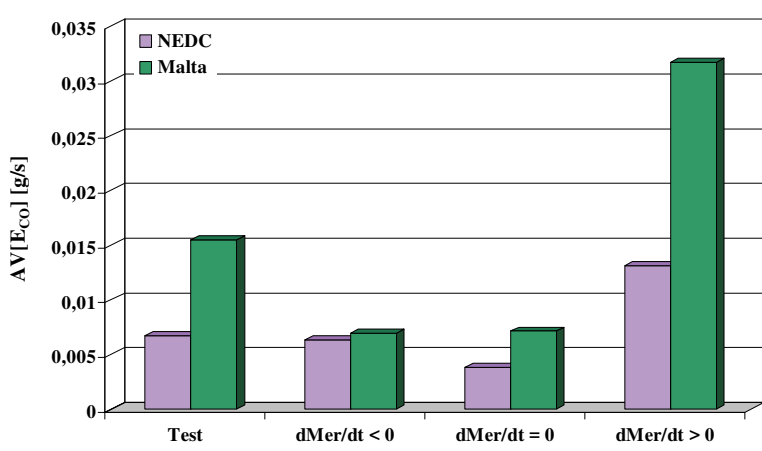

Fig. 28. Comparison of the mean carbon monoxide emission value in the test and in the states corresponding to the negative, zero and positive values of the engine torque derivative with respect to time - for the NEDC and Malta tests

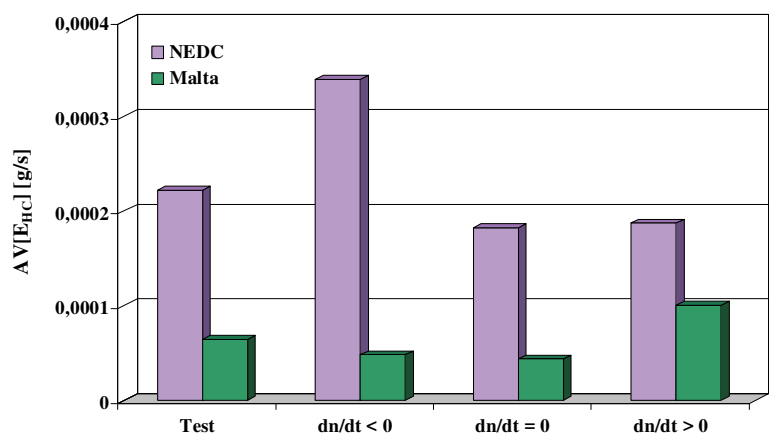

Fig. 29. Comparison of the mean hydrocarbons emission value in the test and in the states corresponding to the negative, zero and positive values of the engine speed derivative with respect to time - for the NEDC and Malta tests

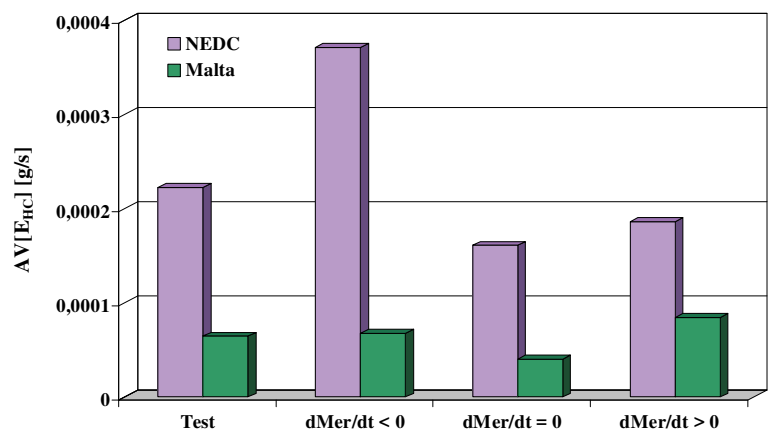

Fig. 30. Comparison of the mean hydrocarbons emission value in the test and in the states corresponding to the negative, zero and positive values of the engine torque derivative with respect to time - for the NEDC and Malta tests

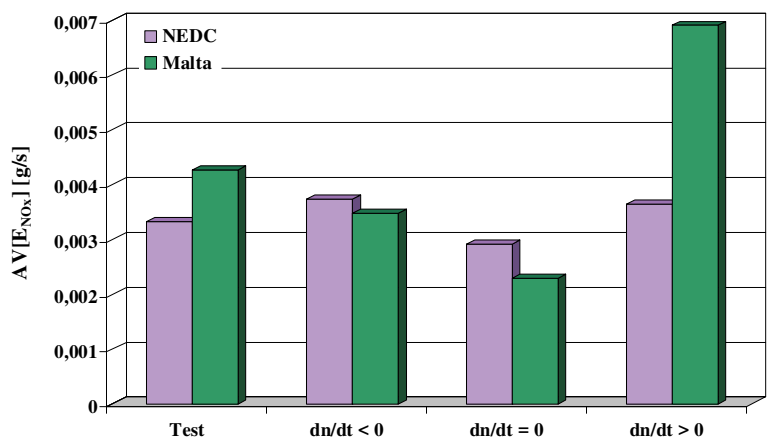

Fig. 31. Comparison of the mean nitrogen oxides emission value in the test and in the states corresponding to the negative, zero and positive values of the engine speed derivative with respect to time - for the NEDC and Malta tests

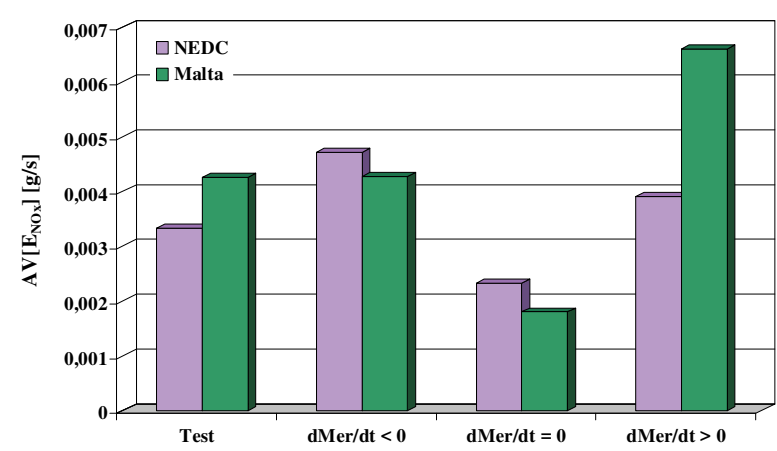

Fig. 32. Comparison of the mean nitrogen oxides emission value in the test and in the states corresponding to the negative, zero and positive values of the engine torque derivative with respect to time - for the NEDC and Malta tests

The sensitivity of exhaust emission values to dynamic states was assessed based on the coefficient of variation of the average exhaust emission intensity value in individual elementary dynamic states - table and fig. 33 and 34.

Table 1 . Coefficient of variation of the average exhaust emission intensity value in individual elementary dynamic states

\begin{tabular}{|c|c|c|c|c|}
\hline & Test & & & \\
\hline Component & & $\mathrm{CO}$ & $\mathrm{HC}$ & $\mathrm{NO}_{\mathrm{x}}$ \\
\hline Dynamic state category & & & & \\
\hline $\mathrm{dn} / \mathrm{dt}$ & \multirow{2}{*}{ NEDC } & 0.666 & 0.377 & 0.130 \\
\hline $\mathrm{dM}_{\mathrm{er}} / \mathrm{dt}$ & & 0.619 & 0.480 & 0.334 \\
\hline $\mathrm{dn} / \mathrm{dt}$ & \multirow{2}{*}{ Malta } & 0.655 & 0.490 & 0.567 \\
\hline $\mathrm{dM}_{\mathrm{er}} / \mathrm{dt}$ & & 0.933 & 0.353 & 0.568 \\
\hline
\end{tabular}

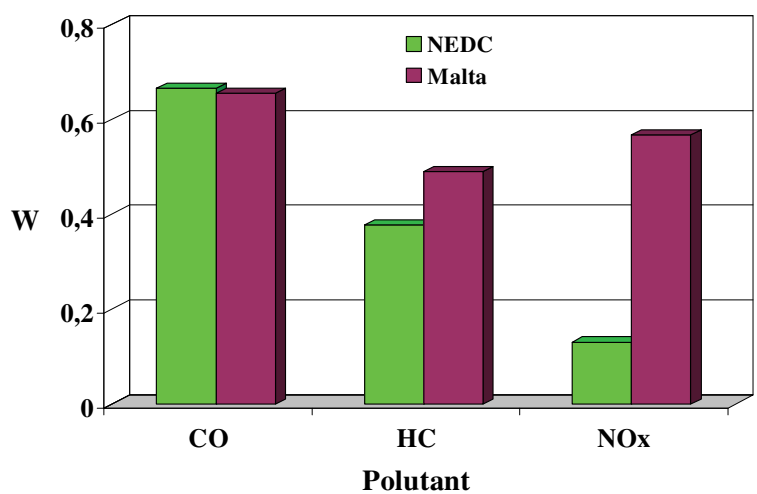

Fig. 33. The coefficient of variation of the average emission intensity value in individual elementary states of dynamic rotational speed variation

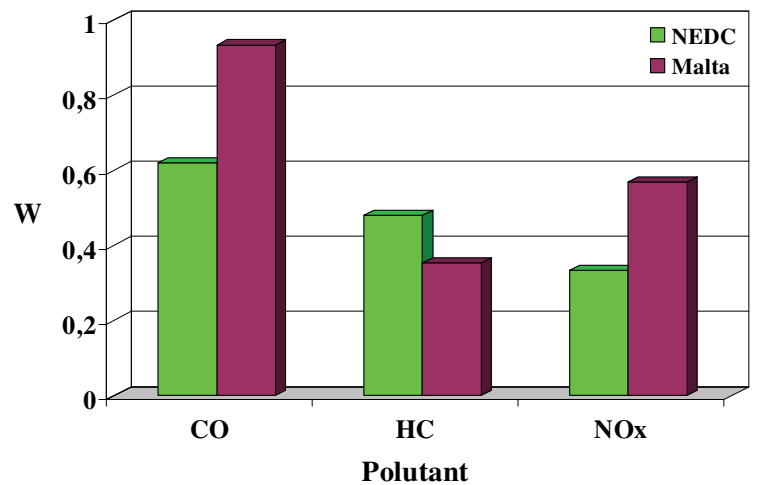

Fig. 34. The coefficient of variation of the average emission intensity value in individual elementary states of dynamic engine torque variation 
In general, the exhaust emission sensitivity to dynamic states for torque changes is higher than for changes in rotational speed. The sensitivity of exhaust emissions to dynamic states for the Malta test was also higher. This is mainly due to the fact that the Malta test is created in accordance with the principle of faithful simulation of car speed characteristic in time and the NEDC test in accordance with the principle of similarity of zero-dimensional characteristics of the speed characteristics. Therefore, the Malta test is characterized by stronger dynamic properties.

The highest sensitivity to dynamic states was found for the mean value of carbon monoxide emission in the Malta test and for torque changes, while the smallest - for the average nitrogen oxide emission intensity in the NEDC test and for rotational speed changes.

More detailed results of the analysis can be carried out for the engine operating conditions related to both rotational speed and relative torque, but such analyzes exceed the volumetric capabilities of this work.

\section{Conclusions}

The article compared exhaust emission in dynamic states in two tests with similar properties: the NEDC test and a Malta test, simulating the NEDC test in road traffic based on the similarities in the average vehicle speed. Dy- namic states corresponding to: decreasing, constant and increasing value of engine speed and torque were considered. The following conclusions can be drawn from the research results:

1. Sensitivity of exhaust emission to dynamic states, differentiated due to the type of dynamic states, the test and the measured substance was found.

2. Generally, the exhaust emission sensitivity to dynamic states is greater for changes in torque than for changes in rotational speed.

3. Overall, the exhaust emissions sensitivity to dynamic states is higher for the Malta test than for the NEDC test.

4. The highest sensitivity to dynamic states was found for the mean emission intensity value of carbon monoxide in the Malta test and for changes in torque.

5. The smallest sensitivity to dynamic states was found for the mean emission intensity value of nitrogen oxides in the NEDC test and for engine speed changes.

6. The purposefulness of analyzing the exhaust emission sensitivity for complex dynamic states, including the combination of engine speed and torque variations, was assessed.

\section{Bibliography}

[1] ANDRYCH-ZALEWSKA, M., CHŁOPEK, Z., MERKISZ, J., PIELECHA, J. Evaluation of the test drive cycle conditions impact on exhaust emissions from an internal combustion engine. Combustion Engines. 2018, 175(4), 3-9.

[2] ANDRYCH-ZALEWSKA, M. Wpływ katalizatora wewnętrznego na emisję spalin w stanach pracy silnika o zapłonie samoczynnym odpowiadających jego użytkowaniu trakcyjnemu. Rozprawa doktorska. Poznań 2018.

[3] ARREGLE, J., BERMUDEZ, V., SERRANO, JR., FUENTES, E. Procedure for engine transient cycle emissions testing in real time. Experimental Thermal and Fluid Science. 2006, 30(5), 485-496.

[4] CHŁOPEK, Z., BIEDRZYCKI, J., LASOCKI, J., WÓJCIK, P. Assessment of the impact of dynamic states of an internal combustion engine on its operational properties. Eksploatacja i Niezawodnosc Maintenance and Reliability. 2015, 17(1), 35-41.

Monika Andrych-Zalewska, DEng. - Faculty of Mechanical Engineering at Wrocław University of Technology.

e-mail: monika.andrych@pwr.edu.pl

Prof. Zdzisław Chłopek, DSc., DEng. - Faculty of Automotive and Construction Machinery Engineering, Warsaw University of Technology.

e-mail: zdzislaw.chlopek@pw.edu.pl
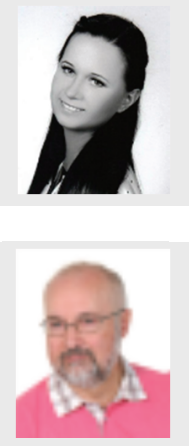

[5] CHŁOPEK, Z. Synthesis of driving cycles in accordance with the criterion of similarity of frequency characteristics. Eksploatacja i Niezawodnosc - Maintenance and Reliability. 2016, 18(4), 572-577.

[6] CHŁOPEK, Z. Some remarks on engine testing in dynamic states. Combustion Engines. 2010, 4(143), 60-72.

[7] MERKISZ, J., GIS, W. Exhaust emission from vehicles under real conditions. Proceedings of the Ninth Asia-Pacific International Symposium on Combustion and Energy Utilization. APISCEU, Beijing 2008.

[8] MERKISZ, J., LIJEWSKI, P., FUĆ, P., WEYMANN, S. Exhaust emission tests from non-road vehicles conducted with the use of PEMS analyzers. Eksploatacja i Niezawodnosc - Maintenance and Reliability. 2013, 15(4), 364-368.

[9] Worldwide emission standards, Passenger cars and light duty vehicles. Delphi. Innovation for the real world. 2016/2017. Prof. Jerzy Merkisz, DSc., DEng. - Faculty of Trans-
port Engineering, Poznan University of Technology.
e-mail: jerzy.merkisz@put.poznan.pl
Prof. Jacek Pielecha, DSc., DEng. - Faculty of Transport Engineering, Poznan University of Technology.

e-mail: jacek.pielecha@put.poznan.pl 